\title{
Anotaciones históricas sobre los primeros años de la Sociedad Colombiana de Obstetricia y Ginecología
}

\author{
Personalidades y hechos. La protección Materno Infantil \\ en la nueva Constitución. Una mirada al futuro.
}

\author{
Carlos R. Silva Mojica
}

Es altamente satisfactorio para mí recibir el reconocimiento y la distinción que hoy me otorga la Sociedad Colombiana de Obstetricia y Ginecología al nombrarme como Miembro Emérito de la misma y presidente honorario de esta sesión solemne. Es cierto que no figuro en la nómina de los miembros fundadores liderados por Rafael Peralta pero sí colaboré activamente en la medida de mis capacidades en sus primeros años de vida.

Pertenecí a la junta directiva como vicepresidente en el año 53, siendo presidente el profesor Arturo Aparicio, secretario general Fernando Tamayo, secretario de actas Hernando Navas y tesorero Santiago Lleras.

También fui director de la Revista desde el año 53 al 56.

Desde su iniciación hasta el presente nuestra Sociedad se ha fortalecido científicamente de manera considerable y ha recibido el reconocimiento internacional por su labor y por su organización como fue puesto de presente en el último congreso de la especialidad celebrado en Montevideo a finales del 90. Como lo anota Francisco Pardo Vargas "El prestigio de una sociedad científica no se improvisa". Ha sido el resultado del esfuerzo, de la voluntad y de la inteligencia de todos aquellos que han ocupado la mesa directiva por más de 40 años.

Es apenas lógico hacer en esta ocasión un reconocimiento de gratitud y aprecio por quienes fueron mis profesores de obstetricia y ginecología: Hernando Acosta Sarmiento, José del Carmen Acosta, Carlos Julio Mojica y Daniel de Brigard.

Mi colaboración tanto en la Sociedad como en la Revista se refiere principalmente a estos cuatro temas: Mortalidad materna, Toxemía gravídica, Complicaciones del parto y Psicoprofilaxis obstétrica, sobre los cuales he hecho numerosas publicaciones.

En forma muy resumida y con un enfoque histórico me referiré a algunos eventos científicos de la Sociedad en sus primeros años de vida en los que colaboré en forma decidida.

Los tres eventos más importantes para mí vida profesional y en los cuales participé y colaboré activamente fueron los siguientes:

1. I Convención Nacional de O.G. Bogotá, 1953.

2. I Seminario de Educación Médica. Cali, 1955. En el cual se sentaron las bases para efectuar más tarde una reforma radical en el sistema de docencia médica.

3. IV Congreso Latinoamericano de O.G. Bogotá, 1962. En el cual expuse conjuntamente con A. Cárdenas Escobar la ponencia oficial de Colombia sobre Psicoprofilaxis obstétrica.
I Convención Nacional de Obstetricia y Ginecología. Bogotá, septiembre 9 a 12/53. Hotel Tequendama. Organizadores: La mesa directiva de ese período, a la cual pertenecía como vicepresidente.

Temas propuestos: Toxicosis gravídica, Factor Rh y eritroblastosis fetal, Esterilidad, Endometriosis y temas libres.

Como tema libre presenté entonces un aporte sobre Mortalidad materna consistente en una revisión estadística de 35.000 embarazos, atendidos en su mayoría en el Instituto Materno Infantil y en el ICSS.

En aquella ocasión no relacionamos la mortalidad materna con el número de nacidos vivos, sino en general con el número total de embarazadas. Estos fueron los hallazgos:

Clínica de Marly: 3.436 embarazadas, 2 fallecidas. Indice de mortalidad: $0.58 \%$.

Hospital San José: 1.200 embarazadas, 4 fallecidas. Indice de mortalidad: $3.3 \%$.

Clínica 1o. de Mayo, ICSS: 18.556 embarazadas, 31 fallecidas. Indice de mortalidad: $1.6 \%$.

Maternidad San Juan de Dios: 11.814 embarazadas, 100 fallecidas. Indice de mortalidad: $8.4 \%$.

Llama la atención la muy baja mortalidad en el ICSS, debido al buen control prenatal, y la alarmante mortalidad en la Maternidad de San Juan de Dios debido a que el $90 \%$ de las pacientes de esta institución no habían recibido ningún control prenatal.

Como causas más frecuentes de mortalidad materna se identificaron estas entidades: 1 . Toxicosis gravídica; 2 . Sepsis, y 3. Hemorragia.

Basado en estos hallazgos hice las siguientes recomendaciones:

1. Intensificar y mejorar el control prenatal.

2. Hacer labor educativa sobre la importancia del cuidado prenatal.

3. Mayor intervencionismo en las toxicosis severas. Intentar salvar las dos vidas. No insistir ante fracaso del tratamiento médico. Acudir a la césarea con más frecuencia.

4. Frente a la sepsis especialmente por maniobras abortivas, resaltar la importancia de la labor educativa.

5. Se desaconseja el método de desprendimiento manual de la placenta en caso de placenta previa. Hacer césarea.

6. Prevención del shock obstétrico (trabajos prolongados, deshidratación, fórceps laboriosos, etc.).

7. Mayor suministro de sangre. Incrementar la fundación de bancos de sangre. 
Al finalizar esta I Convención, se nombró una comisión presidida por el profesor Rafael Peralta para que elaborara las conclusiones. Estas fueron las conclusiones:

\section{Temas obstétricos:}

1. Toxicosis gravídicas. Es alta la mortalidad materno-fetal. Hay controversia en cuanto al tipo de tratamiento. Se debe intentar salvar las dos vidas. Lo mejor: profilaxis y buen control prenatal.

2. Factor Rh. Determinar en toda mujer este factor. Controlar las aglutininas anti $\mathrm{Rh}$ en embarazadas $\mathrm{Rh}(-)$. Control hematológico del hijo de madre Rh (-). Esperar el parto a término en gestantes $\mathrm{Rh}(-)$. Se desaconseja la vía del seno longitudinal superior para transfusiones en recién nacidos.

\section{Temas ginecológicos:}

1. Endometriosis. Apenas se esbozó el tema. Se presentaron 2 trabajos.

2. Esterilidad. Tema novedoso. El Hospital San José ha iniciadio una consulta de esterilidad. Examinar primero al esposo.

\section{Temas libres:}

\section{Merecieron interés los siguientes temas.}

Experiencia con el Embriótomo de Turpín, Gustavo Riaño. - Maniobra de Ramírez Merchán, R. Ramírez M. Mortalidad materna, alarmante en pacientes hospitalarias, C.R. Silva M. - Concepto de encajamiento. Es precoz en primigestantes como excepción pero no como regla, R. Peralta.

\section{Comentario sobre estas conclusiones:}

1. El tema de planificación familiar era "tabú" en aquel entonces. Se requirió la tenacidad de Fernando Tamayo para que introdujera este espinoso tema en nuestro mundo médico y le lavara el cerebro no sólo al público en general sino a sus colegas. Tal vez él expuso en forma amplia este tema por primera vez en el VII Congreso de nuestra especialidad, reunido en Cúcuta en el año 67.

2. El problema de esterilidad se manejaba en ese entonces en una forma muy elemental, y hubiera continuado así si no hubiera sido por la intervención de Elkin Lucena quien marcó un acelerado progreso en estos estudios. Estos dos admirables colegas, Tamayo y Lucena, dejan un valioso mensaje para las nuevas promociones médicas: no es tan importante teorizar, divagar o criticar. Lo esencial es llevar las cosas a la práctica y atreverse a hacerlas.

Reseña de la obra científica del profesor Rafael Peralta, quien presidiera la Comisión de Conclusiones de esta I Convención.

Me referiré únicamente a la publicación de su valioso libro titulado "Obstetricia y Clínica Obstétrica", tomo I, elaborado por la Editorial Antares y entregado al público el 15 de febrero de 1956.

Tratemos de percibir la presencia física y espiritual de Rafael Peralta. Era un amigo cordial y franco. Un médico sumamente estudioso y actualizado, dotado de una envidiable memoria. Era un viajero consumado, recorrió más de medio mundo. Asiduo asistente a los congresos médicos.
Participaba activamente en la parte científica pero también disfrutaba intensamente de los eventos sociales con la alegría y el entusiasmo propios de su espíritu samario. Yo pido el favor a todos los asistentes que nos pongamos de pies y que en honor a su obra científica, a sus méritos y a su personalidad le tributemos un prolongado, caluroso y fuerte aplauso.

Considero que esta obra es fundamental en la historia de la obstetricia en Colombia. Por muchos aspectos es la expresión auténtica de nuestro arte obstétrico colombiano. Como a veces he oído o leído críticas injustas a este tratado, quiero hacer resaltar algunos aspectos positivos de esta obra. Es un libro denso de 830 páginas, profusamente ilustrado: 170 fotograbados, con una extensa bibliografía, 676 referencias en total de las cuales 171 corresponden a autores colombianos. La mayoría de las tesis de grado, especialmente de la Universidad Nacional, elaboradas en esa época, allí están comentadas ampliamente. Personalmente me siento muy gratificado porque allí hay referencias a mi tesis de grado sobre Sufrimiento Fetal y algún otro trabajo publicado en la Revista de la Sociedad. Es muy diciente el hecho de que este libro se inicie con la presentación del Código de Moral Médica lo que habla muy alto del perfil ético, intelectual y científico del profesor Peralta.

En la introducción él pide "a quienes lean este sencillo tratado, que tengan la paciencia obstétrica de savoir attendre, de no precipitarse a la censura injusta, sino que sepa dispensar los errores en que hayamos incurrido y que contribuyan a perfeccionar nuestra obra, con las correcciones que sugieran cordialmente, o haciendo ellos otra mejor, ojalá en un futuro muy próximo".

Lo cierto es que hasta el presente esta obra no ha sido igualada ni superada por ningún autor colombiano, con excepción del "Tratado Integrado de Obstetricia y Ginecología" publicado por el respectivo Departamento de la Facultad de Medicina de la Universidad de Antioquia, obra excelente, en mi concepto, muy completa y muy actualizada. Pero existe una diferencia apreciable.

El libro de Rafael Peralta es obra de un solo autor. De él mismo. En el libro del grupo antioqueño intervinieron 45 colaboradores. También es cierto que en aquella época no se estilaba el trabajo en equipo, por eso Rafael Peralta acometió él solo tamaña empresa. La Sociedad Colombiana de Obstetricia y Ginecología tiene una enorme deuda de gratitud con quien fuera su fundador y uno de los más prominentes profesores de la Universidad Nacional. Me considero muy afortunado de haber podido participar tan directamente en este homenaje que hoy se le rinde.

EL EMBRIOTOMO DE TURPIN. Quiero recordar cómo llegó este aparato a Colombia. Jorge Escamilla, quien había sido interno en el servicio del profesor Mojica en el I.M.I., donde yo era jefe de clínica, había viajado a U.S.A. a completar su entrenamiento gineco-obstétrico. Esto lo estaba haciendo en la ciudad de Augusta, Ga, bajo la direcçión del profesor Richard Turpín, inventor de este aparato y de un taponador uterino, conocido investigador y autor de varios libros. Por intermedio mío hizo llegar estos aparatos al I.M.I.; yo puse en manos del internista Gustavo Riaño el embriótomo para que lo ensayara y presentara una comunicación a la I Convención, como en efecto lo hizo.

Quiero comentar algunos aspectos de la vida profesional 
de mi amigo Escamilla. Después de terminar su entrenamiento en Augusta, se estableció en la ciudad de Brooksville, Fla., donde ha desarrollado una meritoria labor profesional en el campo de la gineco-obstetricia con pacientes privadas y especialmente con pacientes de bajos recursos económicos. Tanto es así que este año recibió una condecoración por sus servicios prestados durante 30 años a pacientes indigentes. Durante estos 30 años él ha actuado como consultor en forma gratuita en la Unidad de Salud Pública del Condado de Hernando. Gracias a su esfuerzo se ha logrado que la mayoría de las embarazadas indigentes reciban un adecuado control prenatal.

Además mi amigo Escamilla se ha distinguido por el sentido de gratitud con sus profesores colombianos y por el amor a su país.

Recientemente me escribe Escamilla y me comenta que lleva más de un año intentando que le publiquen en el Journal OB-GYN un trabajo sobre la maniobra de Ramírez Merchán y que apenas ahora el Dr. Zuspan, director del Journal, le ha dado el visto bueno y que su artículo saldrá publicado en el número de diciembre de este año. De modo que cuando ustedes lean este informe recuerden que el Dr. Escamilla es colombiano, que no ha olvidado a su país ni a sus profesores y que se ha distinguido por su espíritu humanitario y caritativo, aprendido de sus profesores colombianos, lo cual es bastante extraño dentro de la comunıdad médica americana que ha sido señalada por su tendencia definitivamente mercantilista.

Gustavo Riaño, un amigo muy apreciado, desaparecido prematuramente, que también fue interno mío, y discípulo de los profesores Mojica y Acosta, fue un obstetra integral que captó fielmente las enseñanzas de sus maestros. Fue muy prudente en sus conductas y muy cauteloso en sus decisiones. Manejaba muy bien el arte de saber esperar y estar al frente para proteger. Con su especial don de gentes supo ganarse el afecto de sus pacientes, de sus amigos y de sus colegas.

Gustavo Riaño presentó en esta I Convención sus primeras experiencias (13 casos) con el Embriótomo de Turpín y señaló sus principales ventajas: mayor rapidez en la intervención, menor riesgo de ruptura uterina y de sepsis. Como esta técnica despertó tanto interés, Riaño pidió autorización al Dr. Turpín para fabricarlo en Colombia. El permiso le fue concedido y gracias a Gustavo Riaño, este sencillo embriótomo llegó a muchos hospitales de Colombia.

Quiero hacer una breve memoria de la personalidad de Rafael Ramírez Merchán, autor de la mencionada maniobra. Era una personalidad de perfiles muy nítidos, de temperamento fuerte y batallador. Un perfeccionista del arte obstétrico. No transigía con la mediocridad, la mentira, la indecisión o la inmoralidad. Si uno estaba de parte suya había que integrarse a la rigidez de sus principios y a la solidez de su criterio. No se podía estar en contra suya, pues sus polémicas eran contundentes, implacables. Muchos le teníamos envidia pues sabíamos que había que expresar ciertas cosas, pero no lo hacíamos porque no nos atrevíamos a decirlas con la franqueza y vehemencia con que él lo hacía. Temperamentos como el de Ramírez Merchán pasan a la historia y viven en la memoria de quienes los conocieron. Es el caso del colega Jorge Escamilla quien ha hecho todo lo posible por dar a conocer su maniobra en las tierras del Tío Sam.

\section{Tema de actualidad}

La Protección Materno Infantil en la nueva Constitución.

Capítulo 2. Artículo 42: La pareja tiene derecho a decidir libre y responsablemente el número de hijos y deberá sostenerlos y educarlos mientras sean menores o impedidos.

Comentario: No se menciona la necesidad de la Educación para la Vida Familiar y de PLANIFICACION FAMILIAR.

En esta forma se supone que el índice de natalidad seguirá en aumento con grave repercusión en la economía y en la estabilidad social del país.

Artículo 43: Durante el embarazo y después del parto (la mujer) gozará de especial asistencia y protección del Estado y recibirá de éste subsidio alimentario si entonces estuviere desempleada o desamparada. El Estado apoyará de manera especial a la mujer cabeza de familia.

Comentario: Tampoco se menciona la necesidad de la Educación para la Maternidad ni la importancia del control prenatal; se olvidó que es mejor prevenir que curar.

Además, según lo anotado, parece que el Estado no va a prestar asistencia ni protección a la mujer durante el parto, lo cual también es muy importante.

Citamos algunas observaciones sobre la salud en la nueva Constitución, hechas por un profesional muy autorizado.

F. Sánchez Torres (El Tiempo, VIII-6-91).

Principio de Salud Pública:

"Es importante que la gente acuda al Estado cuando está enferma pero es más importante que el Estado acuda a la gente cuando está sana".

Comentario: Esto sí sería educar, prevenir, hacer profilaxis.

\section{El shock gineco-obstétrico del futuro}

Según el estado actual y el progreso de la gineco-obstetricia, me atrevo a presagiar algunos hechos. Así pues, demos una mirada al futuro teniendo en cuenta que en muchos aspectos el futuro ya es hoy.

1. El embarazo y el parto cada vez serán más manipulados e instrumentados.

2. La gineco-obstetricia cada día se verá más deshumanizada.

3. La operación cesárea irá en aumento.

4. Los abortos clandestinos seguirán en aumento.

5. Se legalizará el aborto por indicaciones médicas.

6. Cada día se impondrá más el Sistema de Medicina Prepagada.

7. La inmunología mejorará el pronóstico de la toxemia, del aborto habitual y de la esterilidad.

8. Habrá una amplia aceptación al alquiler de úteros (Maternidad Subrogada).

9. Se generalizarán las técnicas de fertilización in vitro.

10. Habrá mayor demanda de inseminación asistida por parte de mujeres solteras.

11. La manipulación genética seguirá avanzando a pesar de las protestas del Vaticano.

12. Será posible el transplante de úteros en casos seleccionados. 
13. Se implantará como rutina el examen pregestacional.

14. Se crearán servicios especiales para madres drogadictas y enfermas de SIDA y para sus hijos.

15. Seguirán avanzando los estudios de patología fetal, anotando que esto ya se está haciendo en Colombia.

16. Se podrá escoger o programar el sexo de los hijos.

17. Una nueva generación de gineco-obstetras, exclusivamente tecnólogos, tratará de imponerse.

18. Profesionales tradicionalistas verán con reserva la invasión de parafernalia electrónica, usada sin mayor discernimiento.

19. Los docentes de gineco-obstetricia tomarán conciencia de que están formando cirujanos y no obstetras en el verdadero sentido de la palabra.

20. Las sociedades de bioética harán grandes esfuerzos para controlar la avalancha tecnológica.

\section{Comentario final}

Los médicos de la vieja guardia pasaremos a la historia como unos profesionales teóricos, empíricos a veces, que nos guiábamos principalmente por la intuición, la observación, la experiencia, el sentido clínico y el acercamiento afectuoso y humanizado a nuestras pacientes. Esto es para recordar nuestros primeros años de ejercicio profesional en que disponíamos de muy pocos elementos de examen complementario, pero si ejercitábamos un agudo sentido clínico enseñado por nuestros maestros, tampoco es que quiera decir que no conozcamos ni usemos la tecnología. Lo que nos preocupa es el uso indiscriminado de ésta. Sería conveniente que en nuestro país se tuviera en cuenta el llamado "Modelo Sueco" que preconiza un mayor sentido clínico, una humanización de la obstetricia y la utilización de tecnología solamente en casos muy seleccionados. 